\title{
THE EFFECTIVENESS OF USING SCORING RUBRICS IN ACADEMIC WRITING TO ENGLISH-MAJORED STUDENTS
}

\section{Linh Hong Trinh}

\section{Article History}

Received: 10 September 2020

Accepted: 16 November 2020

Published: 30 December 2020

\section{Keywords}

Effectiveness, evaluation, English language teaching, rubrics, academic writing
VNU University of Languages and International Studies, Vietnam Email:linhtrinh1105@gmail.com

\section{INTRODUCTION}

It is universally acknowledged that academic writing has had a central role in students' academic life since it plays a crucial part in the integration of different ideas, the synthesis of various perspectives, and extension of theories which require construction skills and perspective-taking at a high level, as well as greater concern for precision, voice, and audience (Lavelle \& Bushrow, 2007, p. 809). In another word, academic writing serves as a tool of communication that assists learners in conveying their acquired knowledge and demonstrating their critical-thinking skills. As a consequence of being the external sign of an internal thinking process (Bean, 1996, p. 20), academic writing competences are indispensable to English language teaching and learning at the tertiary level. Hence, English academic writing skill is a compulsory subject that every freshman at University of Languages and International Studies (ULIS) has to enrol before they can move to higher levels. According to syllabus provided by teachers of ULIS, the overall goal of this course for writing is to get students exposed to a variety of academic genres of writing and learn the way of doing academic compositions properly.

Regardless of its vital importance, academic writing is of high complexity, making itself one of the toughest tasks for students (Campbell, 2019). Similarly, those first-year students at ULIS frequently confront an array of challenges when studying academic writing. While some of the students are incapable of writing a complete academic essay, others can produce a complete performance but their products are quite random and disorganized. The reason for students' failure in academic writing is their unfamiliarity with criteria of writing compositions which have been clearly illustrated in the writing scoring rubrics. Therefore, it is extremely necessary to make students understand the standards of good writing pieces. More importantly, students also need to be well-informed of their own strengths and weaknesses in academic writing for self-study and self-development. Fortunately, these issues can be handled owing to the use of rubrics as a tool of teaching and learning in writing classes.

Acknowledging the merits of rubrics in teaching academic writing to English-majored freshmen at ULIS, the researcher decided to conduct an action research project to find out the effectiveness of using scoring rubrics in academic writing classes to assist students with their academic writing. Although rubrics are often classified as analytic or holistic rubrics (Alen \& Tanner, 2006; Moskal, 2000), the researcher only chooses analytic rubrics for this study.

\section{LITERATURE REVIEW \\ 2.1. Writing teaching approaches}


Writing has long been known as such a complicated process of teaching and learning which varies greatly among different learners, different teachers and different purposes of the writing classes. Therefore, as Raimes (1983) stated, there is no absolute answer to how teachers should teach writing or what is the best teaching approach to writing. Because of the variety in terms of teaching aims and features of learners, there are many approaches to writing that have been introduced. However, the two most popular ones are product-oriented approach and process-oriented approach.

Product-oriented approach is a traditional technique of teaching writing. In a product-oriented approach, students are encouraged to "mimic a model text" after analyzing the model at an early stage (White and Arndt, 1991). The focus of this approach is on the product that students can generate after learning how to write a composition from analyzing other writing pieces. According to Nunan (1991), the product-oriented approach puts emphasis on the students' action of imitating, copying and transforming the standardized writing supplied by the teachers as a model into their own products. This imitation just includes the students' learning of the format of the writing as well as some common and typical lexical resources for particular types of writing, and learners still have to elicit their own knowledge, grammar and vocabularies to create their writing compositions. However, critics of the application of a product-oriented approach in teaching writing insisted that this approach can just be considered "an exercise in habit formation" (Silva, 1990), which requires neither efforts of thinking nor activation of students' brains. Therefore, this approach will trigger "mindless copies of a particular organizational plan or style" (Eschhloz, 1980) since students learn by imitation rather than thorough understanding and the students' use of language, grammar and vocabulary is just the manipulation of fixed, given patterns (Pincas, 1962).

Unlike product-oriented approach which concentrates on the outcome of the process of teaching and learning writing, process-oriented is seen as an "enabling process" (White and Arndt, 1991) since it emphasizes on the variety of in-class activities to promote the development of language use. According to Graham (1993), in a process-oriented approach, all writing is treated as a creative act which requires students to spend an adequate amount of time and effort to complete. Rather than giving students any models or samples and making learning become imitation of examples, teachers do not intervene in students' writing process. Instead, they facilitate students with their writing by providing help if students need and receive the students' product for correction and feedback. Nunan (1991) clearly stated that although in the process-oriented approach, students cannot get the perfect production or cannot get right from the beginning since the process-oriented approach accept the imperfection in learners' performance at the first stage, it can help learners get closer to perfection through practicing, reflecting, discussing and rewriting. In other words, students can try producing their own compositions, realizing mistakes and self-correcting their own pieces. This can help learners to understand the issues better and remember their mistakes longer.

Process-oriented approach seems to be more complicated than the product-oriented with more main stages in the procedure. First, learners need to generate their own ideas through brainstorming and outlining. This serves as a prewriting stage where students gather information, ideas and supporting details for their writing. There can be discussion among students at this stage so that students can learn from each other and can prepare better for their writing. After brainstorming and outlining, students will write their first draft by themselves without the intervention of teachers. After finishing the first draft, students can exchange their compositions with their classmates to cross check and give comments on each other's performances before they write the second draft. This draft will be checked and commented by teachers and returned to the students so that they can revise their own mistakes and rewrite to improve their performance. These two steps can be repeated many times until the students are sure about how to write academic writing. In this approach, students can promote their creativity since all the writings come from their original thinking. Model texts sometimes can be employed but just as a resource for comparison, not for imitation.

In the chosen writing class for this research, the process-oriented approach is employed since students have already had a certain level of English language, so they are able to write based on their knowledge and language. More importantly, the aim of academic writing is not just to require students to produce some writings, but more than that, they need to understand clearly how to write different styles of writing and write properly in real- life situations.

\subsection{The application of scoring rubrics in writing classes}

In language learning and teaching, rubrics are utilized as "powerful tools for both teaching and assessment", which means not only are rubrics used as an assessment tool, but they also help students to improve their writing skills (Reddy and Andrade, 2010). Hence, rubrics can be applied in writing class to help teachers evaluate students through their performances as well as to assist teachers in their teaching. 
As the main purpose of rubrics is an assessment tool, rubrics are mainly used for formative assessment of students' work while they are in progress (Panadero and Josson, 2013). Teachers will grade students' performances based on the criteria and indicators written in the rubrics, provide students with relevant feedback as well as guide them to better their own performances. More importantly, rubrics are often employed as "a learner-centered approach to assessment" (Reddy and Andrade, 2010), which involves learners more in the process of evaluating their own performances. Since rubrics are quite clear with detailed explanation, students can self-check their own work and peer check their friends' works, thus having the opportunities to reflect their and their friends' writing composition (Sundeen, 2014).

In addition, "rubrics can teach as well as evaluate" (Arter \& McTighe, 2001). As a teaching tool, a scoring rubric helps to clarify teachers' expectations as well as the requirements of the tasks to students; therefore, students can understand the assignments better and are able to know how to meet these requirements. Rubrics can guide and control the learning of students by showing how they will be assessed as well as things that they need to do (Stiggins, 2001). When comparing their work with rubrics, students can understand the teachers' marking better, become aware of their own mistakes and even self-correct their own mistakes. Hence, students can have a better understanding of their problems in writing as well as independently study thanks to the guidance of the rubrics. In the paper of Silva (2014), the effectiveness of using scoring rubrics in instructing academic writing to university students was emphasized. She clarified that when students were fully-equipped with rubrics and explanation in the pre-writing stage, they had better performances compared with others who had to finish the tasks without similar facilitation. Although she concurred with the effectiveness of using rubrics in academic writing classes, Silva (2014) put emphasis on the necessity of informing students of rubrics before using them for instruction. Silva's study (2014) also indicated that there was a lack of students' eagerness to use rubrics to study and self-evaluate if they were not provided enough guidance from teachers. Trinh and Nguyen (2014) shared the same viewpoints with Silva (2014). In their papers, the utilization of rubrics in facilitating learners' writing process was proved to be productive in Vietnamese EFL writing classrooms. On account of exam-driven approach in English language teaching and learning in Vietnamese high schools, students were unable to write a proper composition. Nevertheless, under the employment of rubrics, students became aware of what they needed to do, thus avoiding producing writing pieces that were of low quality or offtrack. Besides, Wang (2017) also justified that the use of scoring rubrics assisted learners to study better in EFL writing classes. Besides, both Andrade (2001) and Wang (2017) believed that learners should be involved in the creation of rubrics in order to make rubrics more suitable for students' needs and their levels. More importantly, the inclusion of students also inspired them to study harder and better with more active participation of learners during class time observed by these researchers. Though Yen (2018) agreed with all the aforementioned opinions about the efficiency of rubrics in teaching academic writing to university students, she revealed that stages in the common procedure of teaching writing should be reordered, by moving forward the rubrics introduction to the pre-writing stage. Similarly, in the research of Andrade, Wang, Du and Akawi (2009), the previous exposure to rubrics in the writing procedure was strongly emphasized with a view to taking advantage of employing rubrics in teaching and learning.

On the other hand, there exists a huge gap between the real situations of the researcher's class and these research articles due to a shortage of research on academic writing in Vietnamese EFL classrooms in general and in universities with the involvement of university students in particular. Although in the study of Trinh and Nguyen (2014), Vietnamese EFL context was analyzed, high school learners were chosen as the targeted participants of this research instead of university students. Consequently, it is essential to conduct research on the innovative method of using marking rubrics in teaching academic writing to English-majored students.

To summarize, rubrics have been used a lot in writing classes, performing the functions of both an assessment tool and a teaching tool, helping the teachers to grade students' performances and assisting students in understanding, self-correcting their own errors and studying from mistakes. In this study, the researcher also employs rubrics as a tool of marking students' performances and guiding students to do their own writing. Analytic rubrics are chosen for teaching academic writing in this course.

\section{RESEARCH METHODS AND RESULTS}

\subsection{Research methods}

On the grounds that subjectivity and sophistication are two outstanding characteristics of English language acquisition, this research adopts qualitative approach as the paradigm and action research as the main methodology. 
In addition, qualitative methods are also utilized as methods for this research, with the employment of three data collecting instruments including observation, semi-structured individual interviews and group interviews. This research involves 150 first-year students majoring in English language teaching or English language interpretation coming from 6 academic writing classes. These participants, with their proficiency of English at level A2, tried to reach level B1 after the course. After observing 150 students in class, the researcher chose 15 students to carry out semi-structured individual and group interviews.

Since action research is "a dynamic and flexible process" (Creswell, 2005) which respects individualism and researchers can employ this type of research in different ways, based on their particular situations, several models of action research have been presented although the steps they follow are quite similar among different models. Under the time constraint of this research, the researcher opts for Kemmis' model (1991) which is not too complicated. He simplifies the procedure into four steps, including planning, acting, observing and reflecting, with the emphasis on the observation and reflection steps which are kept repeated so that the researcher can revise the action plan until she reaches the final results.

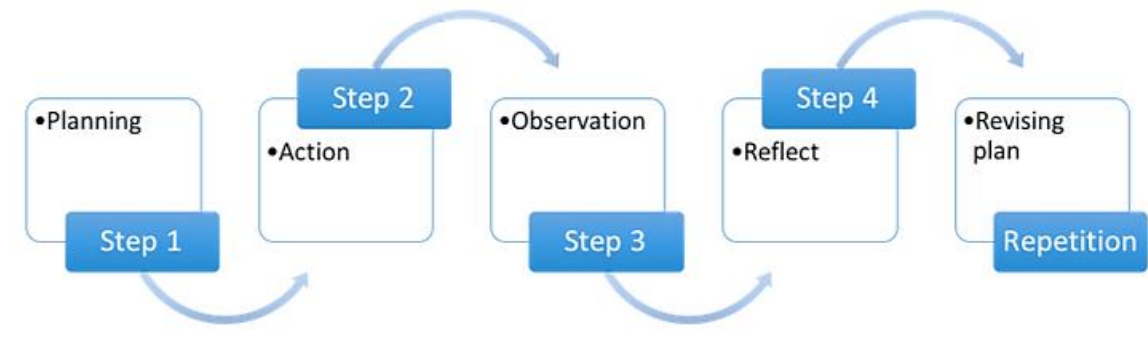

\subsection{Research results}

Figure 1. Kemmis' model of action research (1991)

\subsubsection{The effectiveness of using scoring rubrics in writing classes}

The data gathered from interviews indicated that students found the employment of marking rubrics beneficial to their process of learning English academic writing. Interestingly, this effectiveness was proved regardless of students' levels. In another word, this way of learning was perceived advantageous to both strong and weak learners.

Whilst being questioned in the interviews, the majority of participants responded that the utilization of scoring rubrics in instructing academic writing promoted their comprehension of requirements of writing tasks since they could compare their performances with the marking rubrics. This teaching method enabled students to identify what they had acquired during the learning process and what they needed to do to better their writing skills and ensure the quality of their writing products more easily. To be more specific, during the interviews, student A shared that he could control the quality of his writing by using criteria from the scoring rubrics as guidance for his writing. Sharing the same ideas with informant A, student $\mathrm{K}$ claimed that not only did rubrics guide him in doing an academic composition, they also gave him a complete overview of requirements of the writing tasks as well as the criteria of a good performance so that he could identify his weaknesses and find out how to improve his writing abilities.

During the employment of marking rubrics in teaching academic writing, the task that was utmost favoured by learners was the analysis of one sample writing based on criteria of the rubrics under the collaboration of teacher and learners. According to the feedback of students from both group and individual interviews, this step was reported to be highly effective to all students of different levels, especially weak students. Informants $\mathrm{C}$ and $\mathrm{E}$ elaborated that one impetus for the effectiveness of this activity was the chances to evaluate their classmates' mistakes and reflect their own writing thus self-correcting their own products. Participants F, G, H agreed with informants C and E on the efficiency of sample analysis using rubrics and declared that after this checking session, they could perform better since all of the writing techniques had been embedded deeply in their cognition.

The last activity when using marking rubrics in the academic writing teaching and learning was the design of the rubrics. In the studies of Andrade (2001) and Yen (2018), the inclusion of students in the rubrics design process could make the employment of rubrics more beneficial to students themselves. Nevertheless, while being questioned in this research, a large number of participants, especially weak ones, claimed that this task was unfeasible for them. In contrast, high-level students found their involvement in the creation of marking rubrics meaningful to them. To illustrate, participant L said that her participation in the design of the scoring rubrics granted her deep understanding 
of the requirements of the writing tasks, motivated her through the appreciation of her viewpoints, which was not really common in Vietnamese context.

Regardless of the aforementioned benefits, some drawbacks still existed, which makes this method inapplicable to some students. They gave feedback that despite their complete comprehension of the procedure of the employment scoring rubrics, they were unable to apply it. This problem was encountered by many students although the triggers for these issues were distinct.

A student from the strong group, informant A, complained that the rubrics were too complex for him to understand since the language was very complicated and confusing. Although the teacher made huge efforts to clarify the rubrics to the students, the criteria in the rubrics were described too generally so students did not know how to apply them in their own writing. Moreover, not just one genre of writing was taught during the course but several types were instructed in the same course while only one rubric was used for all, which reduced the adaptiveness of the rubrics.

Although the majority of participants were able to use rubrics confidently to self-evaluate their compositions and correct mistakes or errors in their writing, some depended too much on rubrics, which caused the unequal development in students' writing skills. Informant $\mathrm{N}$ responded that when using rubrics, she succeeded in identifying mistakes in her writing and correcting them. Nevertheless, she concentrated too much on these criteria, leading to her ignorance of other standards in terms of academic writing, which hindered her writing from developing comprehensively.

Andrade et al. (2009) stated that the employment of rubrics in teaching academic writing promoted students' effectiveness in writing English academic genres. Want (2017) further explained this strength of scoring rubrics by clarifying that the interpretation of rubrics granted students a writing guide with respect to the structures of their writing as well as the requirements of the tasks.

This merit of using rubrics was also indicated in the data collected from interviews when participants $\mathrm{K}$ and $\mathrm{A}$ claimed that the use of rubrics was effective in assisting their comprehension of the characteristics and requirements of the writing tasks. Furthermore, the use of rubrics increased students' awareness of writing styles, specifically academic style, as well as the tasks requirements.

\subsubsection{The hindrances of using scoring rubrics in writing classes}

In spite of some evidence from collected data that has shown the effectiveness of using rubrics in academic writing classes, there are several problems that hinder the employment of rubrics in teaching academic writing to English-majored learners in ULIS. These hindrances need to be considered with a view to improving the efficiency of this activity in the long run.

To commence with, as rubrics were created for experts' use, the language features and the content of those rubrics were highly academic, making it challenging for learners to comprehend thoroughly. This drawback was also mentioned in the study of Silva (2014) as well as in the participants' responses in both group and individual interviews. Silva (2014) claimed that there were a lot of complex concepts contained in the rubrics, which demanded prior explanation of the teachers. Whilst being interviewed about what prevented their involvement in using the marking rubrics, informants stated that they misunderstood or were unable to comprehend the rubrics without the interpretation and explanation of teachers. In addition, the marking rubrics were also complained by students in strong groups to be too general with the involvement of numerous terminologies, causing a great deal of difficulties for learners to understand. Additionally, students of both strong and weak groups found the terminologies in the rubrics inexplicable, impeding the process of employing rubrics in academic writing classes. Informant $\mathrm{E}$ as a student in low-level group confessed that he was not really clear about what he could do to add or develop the original version of the rubrics because he did not have enough relevant knowledge or experience.

Another hindrance of using rubrics in teaching academic writing is students' lack of responsibilities and accuracy in self-checking their friends' performances. In some cases, there were certain mistakes that students were unaware of, so when they checked their friends' work, they often ignored those mistakes. Therefore, their friends could not correct their work. Conversely, in other cases, the students were lazy, careless and irresponsible so that they were not willing to identify and suggested the way of correction for every mistake that their friends made, which decreases the effectiveness of the use of rubrics in teaching academic writing.

Last but not least, with an aim to guarantee the reliability of assessment and grading, only rubric existed for all genres of writing as well as all types of assignments. That could ensure the consistency in terms of marking; however, 
it made rubrics hard to be utilized by learners because they were not experienced and professional enough to adapt the given scoring rubrics to different usages or various using contexts. Additionally, rubrics were described too generally. For instance, informants $\mathrm{K}$ and $\mathrm{L}$ stated that one of the criteria mentioned in the scoring rubrics was the variety of lexical items used in their writing. Nevertheless, the extent of the variety was not clarified, which made learners unable to know what they needed to do to meet those requirements.

\subsubsection{Recommendations on the use of scoring rubrics in writing classes}

Based on the merits and demerits of rubrics in teaching academic writing to English-majored students, there are several suggestions to the application of rubrics in writing classes to make rubrics more effective. First and foremost, to learners, because rubrics are quite difficult to comprehend, there must be careful instructions on the use of rubrics and how to employ rubrics properly right from the beginning of the course so that students will be sure what they should do and how they should use the rubrics of writing. In addition, since in this case rubrics just serve a purpose of a tool for students to study and improve their writing skills rather than a tool for teacher to assess their performances, there can be negotiation between teachers and students about the content and the expression of rubrics to make sure that there is a mutual understanding of the content of rubrics between teachers and students. Hence, students can know better about the rubrics and how to use them while teachers can ensure that students will not make mistakes because of their miscomprehension. Furthermore, students will feel motivated because they will be granted the rights to decide which they study and how they study, which means they have freedom in their own studying.

According to participants' feedback on the sophistication of rubrics which makes it hard for learners to understand, it is highly necessary to make rubrics more comprehensible so that the effectiveness of this teaching method can be guaranteed. Different criteria in the scoring rubrics need clarification by adding examples and using Bloom's taxonomy to demonstrate different levels of achievement in each criterion. According to Silva (2014), the complexity of the marking rubrics demanded teachers' facilitation to assist students completely understand these materials, being able to use this instrument of assessment for their learning process. Therefore, when using scoring rubrics for teaching, teachers need to focus more on prior explanation in the pre-writing stage. Additionally, learners participating in this research also suggested that there should be the provision of different rubrics for distinguished genres of writing. Nevertheless, the employment of various rubrics seems unfeasible since it may violate the reliability of assessment when so many instruments are utilized for the same evaluation. In order to solve this issue, the design, interpretation and clarification of rubrics need to be done under the cooperation of teachers and learners to make the rubrics more meaningful to learners because it can assist their understanding of the requirements and facilitate their process of learning academic writing.

Last but not least, to make sure that cross-checking process is effective and mistakes can be avoided, teachers always need to check again the students' performance to make students be more serious and careful about their tasks. In addition, teachers can understand what are the problems with their students' writing and teachers can help with common students' mistakes in the following lessons.

\section{DISCUSSION AND CONCLUSION}

In brief, this action research aimed at investigating the effectiveness of using rubrics to teach writing to Englishmajored students in University of Languages and International Studies. After analyzing carefully and thoroughly the results collected from documents analysis, learning journals and interviews, there have been revealed some main findings concerning the research questions.

First and foremost, the paper discovers that the use of rubrics in teaching and learning writing can help learners to understand how to write a composition better. They will comprehend clearly what they have to do and what are the criteria of a good writing piece. In addition, they will have a chance to use the rubrics to self-reflect their own writing and cross-check their friends' work. Therefore, they can improve their writing by themselves and they can learn from each other as well. In short, the use of rubrics in writing classes not only helps students to study better but also promotes their independent learning as well as their motivation to study.

In addition, there still exist some certain hindrances to the use of rubrics in teaching learning and writing. Because the rubrics are designed for the use of teachers, they are somehow difficult for students to understand. Besides, peer checking among students sometimes are not really accurate due to students' lack of knowledge as well as irresponsibility. To cope with these limitations and improve the use of rubrics in writing teaching and learning, teachers and students should negotiate to reach the mutual understanding in terms of rubrics right from the beginning of the semester or the course to make sure that there will be no mistakes made because of miscomprehension of the 
rubrics and students can understand what they have to do better. Last but not least, teachers need to keep close track of students' peer checking, which means teachers need to review all the peer comments to make sure that students follow the right track and they do their tasks and responsibilities. Thanks to revising the peer checking, teachers can know the problems of students and can help students to correct their own mistakes.

\section{REFERENCES}

Allen, D., \& Tanner, K. (2006). Rubrics: tools for making learning goals and evaluation criteria explicit for both teachers and learners. CBE Life Sci Education, 5(3), 197-203.

Andrade, H. G. (2001). The effects of instructional rubrics on learning to write. Current Issues in Education, 4(4). Retrieved from https://cie.asu.edu/ojs/index.php/cieatasu/article/view/1630

Andrade, H., Wang, X., Du, Y. \& Akawi, R. L. (2009). Rubric-referenced self-assessment and self-efficacy for writing. Educational Theory and Practice Faculty Scholarship, 13.

Arter, J., \& McTighe, J. (2001). Scoring rubrics in the classroom: Using performance criteria for assessing and improving student performance. Thousand Oaks, CA: Corwin/Sage.

Bean, J. C. (1996). Engaging ideas: The professor's guide to integrating writing, critical thinking and active learning in the classroom. San Francisco, CA: Jossey-Bass.

Campbell, M. (2019). Teaching Academic Writing in Higher Education. Education Quarterly Reviews, 2(3), 608-614.

Creswell, J. W. (2005). Educational research, planning, conducting and evaluating quantitative and qualitative research. New Jersey: Prentice Hall.

Eschholz, P. (1980). The prose models approach: Using products in the process. Urbana, IL: National Council of Teachers of English.

Kemmis, S. (1991). Improving education through action research in Zuber-Skerrit Ortrun. Action research in Higher Education. Brisbane: Griffith University.

Lavelle, E., \& Bushrow, K. (2007). Writing approaches of graduate students. Educational Psychology, 6, 807-822.

Moskal, B. M. (2000). Scoring Rubrics: What, When and How?. Practical Assessment, Research, and Evaluation, 7(3). https://doi.org/10.7275/a5vq-7q66

Nunan, D. (1991). Language Teaching Methodology. A Textbook for Teachers. Prentice Hall.

Panadero, E., \& Jonsson, A. (2013). The use of scoring rubrics for formative assessment purposes revisited. Educational Research Review, 9, 129-144.

Pincas, A. (1962). Structural linguistics and systematic composition teaching to students of English as a foreign language. Language Learning, 12(3), 185-194.

Raimes, A. (1983). Techniques in teaching Writing. Oxford: Oxford University Press.

Reddy, Y. M. \& Andrade, H. (2010). A review of rubric use in higher education. Assessment \& Evaluation in Higher Education, 35, 435-448.

Silva, R. D. (2014). Rubrics for assessment: Their effects on ESL students' authentic task performance. $4^{\text {th }}$ CELC Symposium Proceedings, National University of Singapore.

Stiggins, R. J. (2004). Student-involved assessment for learning. Upper Saddle River, NJ: Prentice Hall.

Sundeen, T. H. (2014). Instructional rubrics: effects of presentation options on writing quality. Assessing Writing, $21,74-88$

Trinh Q. L, \& Nguyen, T. T. (2014). Enhancing Vietnamese Learners’ Ability in Writing Argumentative Essays. Journal of Asia TEFL, 11(2), 63-91.

Wang, W. (2017). Using rubrics in student self-assessment: student perceptions in the English as a foreign language writing context. Assessment and Evaluation in Higher Education, 42(8), 1208-1292.

White, R. \& Arndt, V. (1991). Process writing. Harlow, UK: Longman.

Yen, C. A. (2018). Effectiveness of using rubrics for academic writing in an EFL literature classroom. The Asian Journal of Applied Linguistics, 5(1), 70-80. 